\title{
Burnout and Peritraumatic Distress of Healthcare Workers in the COVID-19 Pandemic
}

\section{Yeonhhon Jang}

Seoul National University Graduate School of Public Health

Myoungsoon You ( $\square$ msyou@snu.ac.kr)

Seoul National University https://orcid.org/0000-0001-9869-014X

\section{Heeyoung Lee}

Gyeonggi-do Public Health Institute

\section{Minjung lee}

Seoul National University Graduate School of Public Health

\section{Yeji Lee}

Gyeonggi-do public health institute

\section{Jin-ok Han}

Gyeonggi-do Public Health Institute Jeonghyun Oh

Gyeonggi-do Infectious disease Control center

\section{Research article}

Keywords: COVID-19, Pandemic, Healthcare workers, Mental health, traumatic distress

Posted Date: December 29th, 2020

DOl: https://doi.org/10.21203/rs.3.rs-135151/v1

License: (c) (i) This work is licensed under a Creative Commons Attribution 4.0 International License. Read Full License

Version of Record: A version of this preprint was published at BMC Public Health on November 12th, 2021. See the published version at https://doi.org/10.1186/s12889-021-11978-0. 


\section{Abstract \\ Background}

To evaluate the current status of emotional exhaustion and peritraumatic distress of healthcare workers (HCWs) in the COVID-19 pandemic, and identify factors associated with their mental health status.

\section{Methods}

An online survey involving 1,068 HCWs that included nurses, physicians, and public health officers was conducted. Descriptive statistics and multivariate regression analyses were performed on the collected data.

\section{Results}

Although no significant difference in peritraumatic distress was observed among the surveyed HCWs, the workers' experience of emotional exhaustion varied according to work characteristics. Respondents who were female, older, living with a spouse, and/or full-time workers reported higher levels of emotional exhaustion. Public health officers and other medical personnel who did not have direct contact with confirmed patients and full-time workers had a higher level of peritraumatic distress. Forced involvement in work related to COVID-19, worry about stigma, worry about becoming infected, and perceived sufficiency of organizational support negatively predict emotional exhaustion and peritraumatic distress.

\section{Conclusions}

Job-related and emotional stress of HCWs should not be neglected. Evidence-based interventions and supports are required to protect HCWs from mental illness and to promote mental health of those involved in the response to the COVID-19 pandemic.

\section{Background}

Psychological distress of multiple individuals is intensifying due to the continuing spread of the novel coronavirus, SARS-CoV-2, the virus that causes COVID-19, and the economic downturn caused by COVID19. Accordingly, there is an emerging need for updates to policies concerning COVID-19 to prevent adverse mental health outcomes such as emotional exhaustion and traumatic distress associated with this disease. Healthcare workers (HCWs) in particular have been affected by the COVID-19 pandemic. Medical personnel including physicians, nurses, and public health officers as well as those engaged in epidemiological investigation, contact tracing, management of data for individuals who have confirmed COVID-19, and those suspected of being infected have been working extensively since the early stages of the pandemic. 
Some HCWs have been forced to be involved in efforts to control this infectious disease and the pandemic. Working rapidly under high-pressure and uncertain conditions, HCWs treating COVID-19 patients face challenges associated with increased workloads and high-intensity work. Continuous presence of confirmed COVID-19 cases and mandatory use of personal protective equipment (PPE) in high temperature environments, together with a lack of adequate rest time, have negative impacts on physical and mental health of HCWs and contributes to physical and psychological exhaustion. Previous studies that examined other infectious diseases such as severe acute respiratory syndrome (SARS) and middle east respiratory syndrome (MERS) showed that HCWs can experience serious emotional stress during the outbreak[1-4]. Moreover, outbreaks of infectious disease can increase the likelihood that HCWs will experience burnout, traumatic stress, and other mental health symptoms even after the outbreak $[5,6]$. Emotional exhaustion of HCWs in the COVID-19 pandemic is particularly serious.

Earlier studies reported that female nurses and physicians experienced higher burnout rates than male counterparts [7]. Furthermore, outbreaks of infectious diseases such as SARS, MERS, and avian influenza (Al) increase the anxiety of HCWs during working hours that contributes to traumatic stress $[1,8]$. Peritraumatic distress is emotional and physiological distress experienced during and/or immediately after a traumatic event, and is particularly related to the development and severity of posttraumatic stress disorder (PTSD) and related mental health challenges[9]. In a meta-analysis, peritraumatic distress was associated with PTSD or other psychiatric outcomes[10]. Numerous studies reported that COVID-19 has negative impacts on the mental and psychological health of HCWs and that these impacts are manifested as burnout, depression, anxiety, traumatic stress, and insomnia[11-16].

Such psychological distress could be worsened when people around HCWs avoid them based on stigma or fear $[17,18]$. Stigma, an attribute that extensively discredits an individual, involves subjective perceptions of stigmatization that can be important in predicting health-relevant adverse outcomes[19]. Stigma has negative impacts on mental health[20], and HCWs who are stigmatized reported higher stress[8], especially those who were contact with confirmed patients during the SARS pandemic[18]. Relevant research found that factors relevant to infectious diseases situations, such as shortage of PPE[21] and increased perception of worry about infection, in addition to the availability of support from their organization, can exacerbate or mitigate mental health effects for HCWs.

The lack of effective of vaccines or treatments, and the potential for a second wave of the COVID-19 pandemic in late 2020[22] adds to the emotional burden for HCWs. In this context, the mental well-being of HCWs plays a key role during the pandemic because it is directly related to the maintenance of healthcare systems. The probability that a sustained psychological impact on HCWs can persist even after a pandemic has already been verified[5, 6]. Sustained increases in the number of confirmed patients and a constant influx of suspected cases can increase the vulnerability of HCWs to physical injuries[23], but may also worsen mental health and quality of life, which could in turn affect patient care, as well as directly increase costs at an organizational and societal level to maintain staffing levels of HCWs. Given the unpredictable nature of the COVID-19 pandemic, identifying factors that influence psychological 
distress of HCWs is needed to mitigate the effects of a long period of COVID-19 spread and to establish sustainable infectious disease control systems.

Several studies have examined the mental health of medical staff including nurses and physicians during the COVID-19 pandemic. However, to our knowledge, no studies have simultaneously analyzed medical staff and public health center workers. To control and deal with infectious diseases like COVID-19 properly, determining which occupations involved in responses to COVID-19 have the most serious psychological effects is important, as is identifying which factors influence the psychological wellbeing of these professionals. In this study we examined the varying psychological impacts of COVID-19 on HCWs and other professional involved in the response to COVID-19 and how to alleviate and avoid adverse outcomes associated with this pandemic.

\section{Methods}

\section{Participants and Procedures}

Quantitative data used in this study were collected from HCWs using an online survey conducted in a specific region of South Korea, Gyeonggi-do province, between May 18 and 31, 2020. A license was obtained in order to administer the survey. During the survey period, the region recorded an average of 7.5 newly-confirmed COVID-19 cases and the range was 0-21 new patients per day.

The survey targeted HCWs at 19 hospitals, and 48 institutions engaged in disease prevention in the Gyeonggi-do province. These institutions included the provincial government, and public healthcare centers that work to provide healthcare to patients who were confirmed to have COVID-19 or those who were screened or part of epidemiological investigations. HCWs who were surveyed included: (i) Medical staff working in hospital including nurses, and physicians, and medical technicians; (ii) Field response workers such as epidemiological investigators and public healthcare center officers who were encouraged to voluntarily participate in the survey through an official document; (iii) Nurses and physicians involved in invasive work who had contact with COVID-19 patients or collected saliva or other samples, as well as those involved in diagnostic testing for patient wards or the ICU; (iv) Nurses and technicians engaged in non-invasive work such as consulting, providing education; and ( $v$ ) Workers not directly providing service to confirmed COVID-19 patients such as clerical workers. Workers who performed field work such as managing COVID-19 patient data, performing screening tests, allocating beds for confirmed patients, transferring patients, and conducting field epidemiological investigations were also included in the survey.

\section{Measures}

Dependent Variables 
Respondents completed an online self-report questionnaire that included questions that covered several areas: (1) Emotional Exhaustion and (2) Peritraumatic Distress. Emotional exhaustion of the respondents was measured with Maslach Burnout Inventory (MBI-EE) that included 9 items rated using a 7-point Likert-type scale $(0=$ never, 6 = every day)[24]; the Cronbach's alpha in this study was 0.93 . The Peritraumatic Distress Index (PDI) was used to measure the peritraumatic distress of HCWs. The PDI includes 13 items that assess experiences during work associated with COVID-19. The PDI measures a broad range of emotional and physical reactions to traumatic situations. The index is rated on a 5-point Likert-type scale ranging from 0 to $4(0=$ not at all, $4=$ very much). Inner reliability was 0.89 .

Independent Variables

Independent variables measured included: demographic and work characteristics; worry about stigma; worry about infection; and work-related support. The demographic characteristics of participants included sex $(1=$ male, 2 = female), age, and presence of spouse $(1=$ Yes, $2=$ No). We also collected job-related information, such as occupation ( $1=$ nurse, 2 = doctors, $3=$ technicians, $4=$ public health officer $)$, employment status ( 1 = permanent, $2=$ temporary), and whether the individual had contact with COVID-19 patients $(1=$ yes, $2=$ no $)$.

We developed a stigma questionnaire using three items ranging from 1 (highly disagree) to 4 (highly agree). For example, 'I worry people around me would avoid me because of my work involving COVID-19'; 'I worry people around me would avoid my family due to my work involving COVID-19'. Worry about infection was measured with a single item question, rated on an 11-point Likert-type scale ranging from 0 to $10(0=$ not at all, $10=$ very much $)$.

Respondents were also asked to use an 11-point Likert-type scale $(0=$ very insufficient, $10=$ very sufficient) to rate the perceived sufficiency of support from their organization while working in the COVID19 pandemic, including safety training and education, break time, and psychological support. Finally, study participants reported their perception of the degree of coercive participation in COVID-19 work ( $1=$ strongly disagree, 4 = strongly agree).

\section{Statistical Analysis}

We performed statistical analyses using R version 4.0.2 (R Foundation for Statistical Computing, Vienna, Austria). All descriptive statistic results of quantitative variables were reported as either the number of responses (percentage \%) or mean (M) and standard deviation (SD). We used a t-test and ANOVA to identify differences in responses by demographic factors and occupational factors. To name work types, we combined two job-related variables and recategorized job-related characteristics (i.e., nurses in contact with COVID-19 patients (NC); nurses not in contact with COVID-19 patients (NNC); other medical staff that had contact with COVID-19 patients (MC); other medical staff that did not have contact with COVID-19 patients (MNC); public health officers who had no contacts with COVID-19 patients (PNC)). Multivariate linear regression analyses were performed to examine the effect of demographic factors, job-related 
factors associated with stigma, and work-related support to address peritraumatic distress and emotional exhaustion.

\section{Results}

\subsection{Descriptive statistics}

Descriptive statistics are shown in Table 1. In total, $1,112 \mathrm{HCWs}$ participated in this survey for a $74.1 \%$ response rate. Of these, data for 1,068 respondents were used for the analysis. Among the respondents, $156(14.6 \%)$ were men and $912(85.4 \%)$ were women. The mean age was 35 years-old $(M=35.2, S D=9.1$; range $=20-69$ ) and $54.3 \%$ of respondents had a spouse. Occupation and COVID-19 work type was combined and recategorized as: nurses who did $(n=512)$ and did not $(n=143)$ have contact with confirmed COVID-19 patients; physicians or technicians who did $(n=92)$ and did not $(n=60)$ have contact with confirmed COVID-19 patients; and public health officers not working in contact with patients with COVID-19 $(n=261)$. Among the respondents, $82.3 \%$ were employed full-time.

\section{Table 1 Characteristic of Demographic factors}




\begin{tabular}{|ll|}
\hline Variable & N (\%) \\
\hline Sex & \\
\hline Male & $156(14.6 \%)$ \\
\hline Female & $912(85.4 \%)$ \\
\hline Age & $36.2 \pm 9.1$ \\
\hline$<30$ & $398(37.3 \%)$ \\
\hline $30 \sim 39$ & $352(33.0 \%)$ \\
\hline $40 \sim 49$ & $207(19.4 \%)$ \\
\hline$\geq 50$ & $111(10.4 \%)$ \\
\hline Spouse & \\
\hline Yes & $490(45.9 \%)$ \\
\hline No & $559(52.3 \%)$ \\
\hline Occupation & \\
\hline Doctors, technicians & $152(14.2 \%)$ \\
\hline Nurse & $655(61.3 \%)$ \\
\hline Public health officer & $261(24.4 \%)$ \\
\hline Contact with patients or & \\
\hline suspected & $579(82.3 \%)$ \\
\hline Yes & $189(17.7 \%)$ \\
\hline No & $593(55.5 \%)$ \\
\hline Employment & \\
\hline Full-time & \\
\hline Part-time & \\
\hline
\end{tabular}

\subsection{Mean score of variables}

ANOVA and a post-hoc test were performed for variables that included emotional exhaustion; peritraumatic distress; worry about infection; worry about stigma; and perceived degree of organizational support. Significant differences were found among work type (Table 2). Nurses who worked in contact with confirmed COVID-19 patients showed the highest average score for emotional exhaustion compared to other work types $(p<0.001)$. Tukey's post-hoc tests showed that the trauma stress scores for medical personnel working in contact with COVID-19 patients were significantly lower than those for nurses and 
public health officials. A statistically significant difference in peritraumatic distress was identified among HCWs $(p=0.003)$. Post-hoc tests showed that the PDI score for nurses and PNCs was higher than those for other types of medical providers. Worry about infection was significantly higher for nurses than for $\mathrm{HC}$. In terms of the perception of pressures associated with COVID-19 work participation, PNC were more likely to perceive the participation in COVID-19 work as being coercive relative to other workers $(M=3.7, p$ $<0.001$ ). Differences between occupational characteristics were significant for stigma, and post-test results showed that the worry about stigma by nurses working in contact with COVID-19 patients was significantly higher than that for MNC and PNC. Safety training and education opportunities were considered to be the least sufficient by PNC, whereas MNCs were most likely to indicate that the opportunities were sufficient. Post-test results showed that PNC perceived that the amount of safety training and education was less than that by other professions. MNCs also indicated that they had more education than nurses. PNC showed the lowest degree of sufficient rest time compared to other professions. Post-test results showed that PNC perceived that they had less rest time than $\mathrm{HC}$ and MNC and that NCs perceived having less rest time than HC and MNCs. Finally, the sufficiency of psychological support was the highest for MNC, whereas public health officials had the lowest level. In the post-test, NC and PHC indicated that availability of psychological support was less than that of HC and MNC. 
Table 2

Descriptive statistics of variables by job characteristics

\begin{tabular}{|c|c|c|c|c|c|c|c|c|}
\hline Variable & M & SD & $\begin{array}{l}\text { Nurse } \\
\text { (contact) }\end{array}$ & $\begin{array}{l}\text { Nurse } \\
\text { (no } \\
\text { contact) }\end{array}$ & $\begin{array}{l}\text { Other } \\
\text { medical } \\
\text { staffs } \\
\text { (contact) }\end{array}$ & $\begin{array}{l}\text { Other } \\
\text { medical } \\
\text { staffs } \\
\text { (no } \\
\text { contact) }\end{array}$ & $\begin{array}{l}\text { Public } \\
\text { health } \\
\text { officer } \\
\text { (No } \\
\text { contact) }\end{array}$ & $p$ \\
\hline $\begin{array}{l}\text { Emotional } \\
\text { Exhaustion }\end{array}$ & 30.8 & 12.5 & $\begin{array}{l}32.5 \pm \\
11.4\end{array}$ & $\begin{array}{l}30.8 \pm \\
11.5\end{array}$ & $\begin{array}{l}23.6 \pm \\
13.6\end{array}$ & $\begin{array}{l}25.8 \pm \\
13.2\end{array}$ & $\begin{array}{l}31.2 \pm \\
13.5\end{array}$ & $\begin{array}{l}< \\
0.001\end{array}$ \\
\hline $\begin{array}{l}\text { Peritraumatic } \\
\text { Distress }\end{array}$ & 19.1 & 9.1 & $\begin{array}{l}19.2 \pm \\
8.9\end{array}$ & $\begin{array}{l}19.8 \pm \\
8.7\end{array}$ & $\begin{array}{l}16.0 \pm \\
10.0\end{array}$ & $\begin{array}{l}17.5 \pm \\
8.8\end{array}$ & $\begin{array}{l}20.0 \pm \\
9.5\end{array}$ & 0.003 \\
\hline $\begin{array}{l}\text { Worry for } \\
\text { infection }\end{array}$ & 6.6 & 2.3 & $6.8 \pm 2.2$ & $6.8 \pm 2.1$ & $6.0 \pm 2.7$ & $6.1 \pm 2.6$ & $6.5 \pm 2.3$ & 0.002 \\
\hline $\begin{array}{l}\text { Perception of } \\
\text { Coercive } \\
\text { Participation in } \\
\text { the COVID-19 } \\
\text { Work }\end{array}$ & 3.1 & 1.2 & $2.9 \pm 1.2$ & $2.7 \pm 1.2$ & $2.8 \pm 1.4$ & $2.7 \pm 1.1$ & $3.7 \pm 1.1$ & $\hat{0}_{0.001}$ \\
\hline $\begin{array}{l}\text { Worry for } \\
\text { stigma }\end{array}$ & 2.4 & 1 & $2.6 \pm 0.9$ & $2.3 \pm 0.9$ & $2.3 \pm 1.0$ & $2.1 \pm 0.9$ & $2.2 \pm 1.0$ & $\begin{array}{l}<.001 \\
0.00\end{array}$ \\
\hline $\begin{array}{l}\text { Training, } \\
\text { Education for } \\
\text { Safety }\end{array}$ & 5.8 & 2.4 & $5.9 \pm 2.2$ & $5.9 \pm 2.1$ & $6.2 \pm 2.5$ & $7.1 \pm 2.2$ & $4.9 \pm 2.5$ & $\begin{array}{l}< \\
0.001\end{array}$ \\
\hline Breaktime & 4.8 & 2.8 & $4.8 \pm 2.6$ & $4.9 \pm 2.5$ & $5.7 \pm 2.9$ & $6.0 \pm 2.7$ & $4.3 \pm 2.9$ & $\begin{array}{l}< \\
0.001\end{array}$ \\
\hline $\begin{array}{l}\text { Psychological } \\
\text { support }\end{array}$ & 3.5 & 2.5 & $3.3 \pm 2.5$ & $3.9 \pm 2.4$ & $4.2 \pm 2.8$ & $4.4 \pm 2.8$ & $3.2 \pm 2.4$ & $\begin{array}{l}<.001 \\
0.001\end{array}$ \\
\hline
\end{tabular}

To determine whether these differences were clinically meaningful, the prevalence of high scores was calculated (Table 3). The prevalence of indicators of peritraumatic distress during the COVID-19 pandemic was higher for NNC, however, no statistical significance was observed among work characteristics $\left(\chi^{2}=6.28, p=0.179\right)$. The prevalence of emotional exhaustion was highest for NC $(70.7 \%)$, followed by NCN (66.4\%) and PNC (60.2\%); these differences were statistically significant $(\chi 2=43.33, p=$ $0.179)$. 
Table 3

Prevalence of adverse outcomes in the COVID-19 healthcare workers

\begin{tabular}{|c|c|c|c|c|c|c|}
\hline & $\begin{array}{l}\text { Nurse } \\
\text { (contact) }\end{array}$ & $\begin{array}{l}\text { Nurse } \\
\text { (no } \\
\text { contact) }\end{array}$ & $\begin{array}{l}\text { Other } \\
\text { medical } \\
\text { staffs } \\
\text { (contact) }\end{array}$ & $\begin{array}{l}\text { Other } \\
\text { medical } \\
\text { staffs } \\
\text { (no contact) }\end{array}$ & $\begin{array}{l}\text { Public } \\
\text { health } \\
\text { officer } \\
\text { (No contact) }\end{array}$ & $\mathbf{p}$ \\
\hline $\mathrm{N}$ & 512 & 143 & 92 & 60 & 261 & \\
\hline $\begin{array}{l}\text { Peritraumatic } \\
\text { Distress }(\geq 23)\end{array}$ & $\begin{array}{l}177 \\
(34.6 \%)\end{array}$ & $\begin{array}{l}55 \\
(38.5 \%)\end{array}$ & 25 (27.2\%) & $14(23.3 \%)$ & 89 (34.1\%) & 0.179 \\
\hline $\begin{array}{l}\text { Emotional } \\
\text { Exhaustion }(\geq 27)\end{array}$ & $\begin{array}{l}362 \\
(70.7 \%)\end{array}$ & $\begin{array}{l}95 \\
(66.4 \%)\end{array}$ & 38 (41.3\%) & $26(43.3 \%)$ & $157(60.2 \%)$ & $\begin{array}{l}<.001 \\
0.001\end{array}$ \\
\hline
\end{tabular}

3.3 Factors that influence emotional exhaustion and peritraumatic distress of HCWs in the COVID-19 pandemic

Multivariate linear regression was performed to identify factors that affect emotional exhaustion and peritraumatic distress of healthcare workers during the COVID-19 pandemic (Table 4). Female, full-time healthcare providers had higher rates of emotional exhaustion, whereas respondents who were younger, and who those who had a spouse had lower emotional exhaustion. COVID-19 work participation pressure $(\beta=1.58, p<0.001)$, worry about stigma $(\beta=1.93, p<0.001)$, and worry about infection $(\beta=0.65, p<0.01)$ were positive and significant predictors, whereas perception of breaktime sufficiency $(\beta=-0.54, p<$ $0.001)$, and psychological support $(\beta=-0.66, p<0.001)$ were significantly negative predictors of workrelated emotional exhaustion of HCWs. These factors accounted for $31.4 \%$ of the variance in emotional exhaustion $\left(F[14,1053]=35.95\right.$, adjusted $\left.R^{2}=0.314, p<0.001\right)$. 
Table 4

Multivariate Regression of Peritraumatic Distress

\begin{tabular}{|c|c|c|c|c|}
\hline \multirow[b]{2}{*}{ Predictors } & \multicolumn{2}{|c|}{$\begin{array}{l}\text { Work-related Burnout } \\
\text { (Exhaustion) }\end{array}$} & \multicolumn{2}{|c|}{$\begin{array}{l}\text { Peritraumatic } \\
\text { Distress }\end{array}$} \\
\hline & Estimates & std. Error & Estimates & $\begin{array}{l}\text { std. } \\
\text { Error }\end{array}$ \\
\hline Constants & $21.02^{\star \star \star}$ & 2.52 & 3.81 * & 1.9 \\
\hline Sex [ref: male] & $4.64^{\star \star \star}$ & 1.01 & 1.49 & 0.76 \\
\hline Age & $-0.09^{*}$ & 0.05 & 0.01 & 0.04 \\
\hline Presence of spouse [ref: no] & $-3.47^{* \star \star}$ & 0.81 & -1.15 & 0.61 \\
\hline $\begin{array}{l}\text { Nurse (No contact) [ref: Nurse } \\
\text { (Contact)] }\end{array}$ & 0 & 0.99 & 1.47 & 0.75 \\
\hline Other medical staffs (contact) & -2.07 & 1.32 & 0.2 & 1 \\
\hline Other medical staffs (No contact) & 1.5 & 1.56 & $2.43^{*}$ & 1.17 \\
\hline Public health officers (No contact) & 0.42 & 0.93 & $2.09^{* *}$ & 0.7 \\
\hline Employment [ref: part-time] & $3.79^{\star \star \star}$ & 0.94 & $1.94^{* *}$ & 0.71 \\
\hline Coercive participation & $1.58^{\star \star \star}$ & 0.28 & $0.56^{* *}$ & 0.21 \\
\hline Worry for stigma & $1.93^{* \star *}$ & 0.36 & $2.96^{* * *}$ & 0.27 \\
\hline Worry for infection & $0.65^{\star \star \star}$ & 0.15 & $0.89^{\star \star \star}$ & 0.11 \\
\hline Training and education for safety & -0.23 & 0.16 & -0.28 * & 0.12 \\
\hline Breaktime & $-0.54^{* \star \star}$ & 0.15 & $-0.24^{*}$ & 0.11 \\
\hline Psychological support & $-0.66^{* \star *}$ & 0.17 & -0.08 & 0.13 \\
\hline Observations & 1068 & & & \\
\hline $\mathrm{R}^{2} / \mathrm{R}^{2}$ adjusted & $0.323 / 0.314$ & & $0.278 / 0.2$ & \\
\hline$* p<0.05 * * p<0.01 \quad * * * p<0.001$ & & & & \\
\hline
\end{tabular}

For peritraumatic distress, MNC, PNC, and full-time HCWs showed higher PDI scores compared to other work types. Perceived COVID-19 work participation pressure $(\beta=0.56, p<0.01)$, worry about stigma $(\beta=$ $2.96, p<0.001)$, and worry about infection $(\beta=0.89, p<0.001)$ had a positive effect on peritraumatic distress of the respondents. Peritraumatic distress was negatively associated with perceived sufficiency of safety training and education $(\beta=-0.28, p=0.02)$, and amount of breaktime $(\beta=-0.24, p=0.03)$. These 
factors accounted for $26.8 \%$ of the variance in peritraumatic distress $\left(F[14,1053]=28.97\right.$, adjusted $R^{2}=$ $0.268, p<0.001)$.

\section{Discussion}

Our study reported psychological distress of HCWs including nurses, physicians, and public health officers. We found that emotional exhaustion of HCWs is highly serious, as evidenced by an average score (30.8) that was higher than the prevalence cut-off point (27). The prevalence of emotional exhaustion of this study was $63 \%$, which was worse than that for studies concerning SARS or MERS [5, 25]. In particular, the prevalence of burnout among nurses was the highest of the different work types examined. This result is similar to that reported in other related COVID-19 studies[26]. The higher prevalence of emotional exhaustion could be attributed to long-term COVID-19 work participation, having to work in a risky workplace, and continuous presence of COVID-19 related tasks[5, 7]. The traumatic distress of staff working in public health centers was worse than that for any other type of HCW. These results (Table 4) indicated that more attention to mental health wellbeing of nurses caring for COVID-19 patients is needed[12]. There was no significant difference in the prevalence of PDI among work characteristics, but the mean PDI score for public health officers was statistically higher than that for respondents engaged in other types of work. Furthermore, although the mean score for emotional exhaustion for NC was the highest of the work types examined, the scores for PNC were as high as the exhaustion scores for nurses. This result implies that first-line medical workers do not always have higher psychological distress than other workers, and highlights that supports such as provision of rest time, safety training and education, and psychological support are needed for all types of HCWs, regardless of their job type and obligations[15]. Based on previous reports concerning the relationship between exhaustion and psychological distress[27, 28], future research should consider the importance of psychological wellbeing of HCWs.

The results of multiple regression analyses showed that full-time employment and the perception that COVID-19 work participation was compulsive were negatively associated with psychological distress. This result could reflect the conflicting obligations of duty to care for COVID-19 patients on the one hand and the drive for self-preservation on the other. Full-time HCWs are exposed to higher risks from COVID-19 compared to part-time workers simply based on the number of hours worked. Due to their full-time status, such HCWs are more likely to be placed on response teams, which can enhance feelings of stress and perception that participation in the work is mandatory. As an infectious disease outbreak can result in decreased willingness to work[29-33], compulsory work may exacerbate negative impacts on psychological well-being in that conflicts between work obligations and worry about infection can affect mental wellbeing.

Difficulties in the workplace including insufficient break time, concern for safety, and long-term workload can also contribute to psychological distress of HCWs in the COVID-19 pandemic. Previous research found that there is indeed an association between physical health problems and workplace environmental stressors[13, 21]. Contact with confirmed COVID-19 patients or those suspected of having 
COVID-19, the possibility of being infected, and stigma could worsen the psychological wellbeing of HCWs[14].

The results of the present study were consistent with previous studies and showed that stigma influenced psychological health or mental illness[20,34]. Stigmatization of HCWs affects their psychological and physical health $[8,20,34,35]$. Particularly during outbreaks of infectious diseases, HCWs who had contact with confirmed patients felt more stigma compared to other workers. Thus, preventing stigma of HCWs is an important issue that should be addressed during catastrophic situations including pandemics[36-38]. Hospital administrators and policymakers should take appropriate actions to ensure that HCWs do not suffer from pandemic-related stigma and minimize negative effects from stigma that may occur[39].

Psychological distress of HCWs could persist for years after the outbreak, and this sustained psychological distress would be expected to have adverse effects on the physical health of these workers $[5,6,40]$. Thus, development of evidence-based interventions is needed to prevent adverse mental health problems among HCWs. The current study found that psychological supports could mitigate emotional exhaustion of HCWs who are treating patients with COVIC-19, which is a similar to that reported in an earlier study [37]. Breaktime, safety training and education, and psychological support all improve mental health of HCWs[11, 41]. In this context, individual and organizational interventions need to be initiated for HCWs. Strategies such as mindfulness practices and leveraging of positive psychology resources that are readily available to individual HCWs could help them manage their mental wellbeing[42-44]. Another important factor that might minimize HCW burnout and traumatic stress are altruistic behaviors, which are negatively related to traumatic stress[45]. Organizations including hospitals, clinics, and public health institutions need to provide sufficient training and exercises to provide psychological support for employees that would mitigate the negative impact of infectious disease outbreaks on mental health[46], and guarantee sufficient rest time or flexible working hours[47]. Routine support from colleagues and supervisors enhance the perception by HCWs that they are being protected[23, 48]. Mobile health tools[49], telephone helplines[11], or digital learning packages[50] are other approaches to reduce and manage their mental illnesses associated with working during an infectious disease outbreak.

The strength of this study is that we surveyed both medical staff and public health officers who, unlike nurses or physicians, are typically not considered in studies of the psychological impacts of disease outbreaks. In South Korea, there is a tendency to recognizes HCWs as only including nurses and physicians. Our examination of the mental health status of public health workers in the present study could be helpful for the lay public to recognize the extent of the effects on these workers by disease outbreaks. In this study we estimated the traumatic distress of HCWs using PDI. Although most of the relevant studies use PTSD scales to estimate traumatic distress, consideration of peritraumatic distress could reveal traumatic distress during or right after the disease outbreak.

This study does have several limitations. First, there was a bias in the type of survey respondent. More than half of the participants were nurses and few physicians responded to the survey. Furthermore, only 
those HCWs living in Gyeonggi-do were included in the survey. Second, the variables for an objective index of work, for instance, number of hours spent working with patients with COVID-19, was not determined. We were only able to identify associations between adverse outcomes and perception and respondents' perceptions. Finally, since this was a cross-sectional study, the significant association between psychological distress and organizational support (i.e., training, education, break time, psychological support) may not imply a causal relationship. Due to the characteristics of the PDI, we could only examine the short-term effect of COVID-19 situation on mental wellbeing of HCWs. As such, follow-up research is needed to identify long-term negative impacts of disease outbreaks on mental health aspects of HCWs such as PTSD.

\section{Conclusion}

Our study highlights that HCWs working with patients with COVID-19 are emotionally exhausted not only by affective psychological factors (e.g., worry about stigma) but also by increased work demands during the outbreak. Regardless of occupation and work characteristic, the distress level among HCWs must be managed in a timely manner. Highly challenging working conditions of HCWs involved in COVID-19 responses could increase the risk of mental health problems. Intense workloads contribute to exhaustion of HCWs that can threaten their mental wellbeing. Thus, continuous monitoring to manage the mental health of HCWs should be implemented. Efforts devoted to early detection and prevention of mental health problems of HCWs should be put into place. Early evidence-based interventions are needed not only to maintain mental health of HCWs but also to prevent negative consequences of mental health impacts on HCWs for organizations and the overall society.

\section{Abbreviations}

COVID-19: Coronavirus disease 2019; HCW:Healthcare Workers; NC:nurses in contact with COVID-19 patients; NNC:Nurses not in contact with COVID-19 patients; MC:other medical staff that had contact with COVID-19 patients; MNC:Other medical staff that did not have contact with COVID-19 patients;

PNC:Public health officers who had no contacts with COVID-19 patients; PDI:Peritraumatic distress Index; M:Mean; SD:Standard deviation.

\section{Declarations}

\section{Ethics approval and consent to participate}

This study protocols for the collection and analyses of the survey data were approved by the ethics committee of Bundang Seoul National University Hospital (No: B-2005/615-304). Respondents read written description of the study, voluntarily consented to participate the survey.

\section{Consent for publication}

Not applicable. 


\section{Availability of data and materials}

There is no public access to all data generated or analyzed during this study to preserve the privacy of the identities of the individuals. The dataset that supports the conclusions is available to the corresponding author upon request.

\section{Competing interests}

The authors declare that the research was conducted in the absence of any commercial of financial relationships that could be constructed as a potential conflict of interests.

\section{Funding}

This work was supported by the Gyeonggi-do Public Health Policy Institute, funded by the Gyeonggi-do Province Government, South Korea. The funding body had roles in the design of the study, data collection and analysis.

\section{Authors' contributions}

YH conceptualized the study, MS, HY designed survey and interpreted data; $\mathrm{YH}, \mathrm{YJ}, \mathrm{JO}, \mathrm{JH}$ performed the survey; YH drafted the manuscript; MS, MJ, YJ critically reviewed and improved the manuscript; MS improved data interpretation and revised the manuscript. All authors substantially contributed to the study and approved its submission.

\section{Acknowledgments}

The authors would like to thank the healthcare workers who participated in this survey.

\section{References}

1. Lee, S.M., et al., Psychological impact of the 2015 MERS outbreak on hospital workers and quarantined hemodialysis patients. Comprehensive Psychiatry, 2018. 87: p. 123-127.

2. Tam, C.W.C., et al., Severe acute respiratory syndrome (SARS) in Hongkong in 2003: Stress and psychological impact among frontline healthcare workers. Psychological Medicine, 2004. 34(7): p. 1197-1204.

3. Maunder, R.G., et al., Factors associated with the psychological impact of severe acute respiratory syndrome on nurses and other hospital workers in Toronto. Psychosom Med, 2004. 66(6): p. 938-42.

4. Chua, S.E., et al., Psychological Effects of the SARS Outbreak in Hong Kong on High-Risk Health Care Workers. The Canadian Journal of Psychiatry, 2004. 49(6): p. 391-393.

5. Maunder, R.G., et al., Long-term psychological and occupational effects of providing hospital healthcare during SARS outbreak. Emerg Infect Dis, 2006. 12(12): p. 1924-32. 
6. Lancee, W.J., et al., Prevalence of psychiatric disorders among Toronto hospital workers one to two years after the SARS outbreak. Psychiatric services (Washington, D.C.), 2008. 59(1): p. 91-95.

7. Barello, S., L. Palamenghi, and G. Graffigna, Burnout and somatic symptoms among frontline healthcare professionals at the peak of the Italian COVID-19 pandemic. Psychiatry Research, 2020. 290.

8. Maunder, R., The experience of the 2003 SARS outbreak as a traumatic stress among frontline healthcare workers in Toronto: lessons learned. Philos Trans R Soc Lond B Biol Sci, 2004. 359(1447): p. 1117-25.

9. Brunet, A., et al., The Peritraumatic Distress Inventory: A proposed measure of PTSD criterion A2. American Journal of Psychiatry, 2001. 158(9): p. 1480-1485.

10. Vance, M.C., et al., Peritraumatic distress: A review and synthesis of 15 years of research. J Clin Psychol, 2018. 74(9): p. 1457-1484.

11. Kang, L., et al., Impact on mental health and perceptions of psychological care among medical and nursing staff in Wuhan during the 2019 novel coronavirus disease outbreak: A cross-sectional study. Brain, Behavior, and Immunity, 2020. 87: p. 11-17.

12. Lai, J., et al., Factors Associated With Mental Health Outcomes Among Health Care Workers Exposed to Coronavirus Disease 2019. JAMA Network Open, 2020. 3(3): p. e203976-e203976.

13. Hu, D., et al., Frontline nurses' burnout, anxiety, depression, and fear statuses and their associated factors during the COVID-19 outbreak in Wuhan, China: A large-scale cross-sectional study. EClinicalMedicine, 2020: p. 100424.

14. Zhang, W.-r., et al., Mental health and psychosocial problems of medical health workers during the COVID-19 epidemic in China. 2020. 89(4): p. 242-250.

15. Tan, B.Y., et al., Psychological impact of the COVID-19 pandemic on health care workers in Singapore. 2020.

16. Stuijfzand, S., et al., Psychological impact of an epidemic/pandemic on the mental health of healthcare professionals: a rapid review. BMC Public Health, 2020. 20(1): p. 1230.

17. Organization, W.H., Mental health and psychosocial considerations during the COVID-19 outbreak, 18 March 2020. 2020, World Health Organization.

18. Verma, S., et al., Post-SARS psychological morbidity and stigma among general practitioners and traditional Chinese medicine practitioners in Singapore. Ann Acad Med Singapore, 2004. 33(6): p. 743-8.

19. Major, B. and L.T.J.A.R.P. O'brien, The social psychology of stigma. 2005. 56: p. 393-421.

20. Cluver, L.D., F. Gardner, and D. Operario, Effects of Stigma on the Mental Health of Adolescents Orphaned by AIDS. Journal of Adolescent Health, 2008. 42(4): p. 410-417.

21. Shechter, A., et al., Psychological distress, coping behaviors, and preferences for support among New York healthcare workers during the COVID-19 pandemic. General Hospital Psychiatry, 2020. 66: p. 1-8. 
22. Xu, S. and Y. Li, Beware of the second wave of COVID-19. The Lancet, 2020. 395(10233): p. 13211322.

23. Greenberg, N., et al., Managing mental health challenges faced by healthcare workers during covid-19 pandemic. The BMJ, 2020. 368.

24. Maslach, C., S.E. Jackson, and M.P. Leiter, MBI: Maslach burnout inventory. 1996: CPP, Incorporated Sunnyvale, CA.

25. Boudreau, R.A., et al., The pandemic from within: Two surveys of physician burnout in Canada. Canadian Journal of Community Mental Health, 2006. 25(2): p. 71-88.

26. Matsuo, T., et al., Prevalence of Health Care Worker Burnout During the Coronavirus Disease 2019 (COVID-19) Pandemic in Japan. JAMA Network Open, 2020. 3(8): p. e2017271-e2017271.

27. Shenoi, A.N., et al., Burnout and Psychological Distress Among Pediatric Critical Care Physicians in the United States*. Critical Care Medicine, 2018. 46(1).

28. Zou, G., et al., Correlates of psychological distress, burnout, and resilience among Chinese female nurses. Industrial health, 2016. 54(5): p. 389-395.

29. Barnett, D.J., et al., Assessment of local public health workers' willingness to respond to pandemic influenza through application of the extended parallel process model. PLoS One, 2009. 4(7): p. e6365.

30. Park, Y.S., L. Behrouz-Ghayebi, and J.J. Sury, Do shared barriers when reporting to work during an influenza pandemic influence hospital workers' willingness to work? A multilevel framework. Disaster Medicine and Public Health Preparedness, 2015. 9(2): p. 175-185.

31. Gershon, R.R., et al., Factors associated with the ability and willingness of essential workers to report to duty during a pandemic. J Occup Environ Med, 2010. 52(10): p. 995-1003.

32. Chaffee, M., Willingness of health care personnel to work in a disaster: an integrative review of the literature. Disaster Med Public Health Prep, 2009. 3(1): p. 42-56.

33. Jang, Y., et al., Factors Associated with Hospital Workers' Intention to Work in South Korea During the Early Stages of the COVID-19 Outbreak. Disaster Medicine and Public Health Preparedness, 2020: p. 1-17.

34. Ramaci, T., et al., Social Stigma during COVID-19 and its Impact on HCWs Outcomes. 2020. 12(9): p. 3834.

35. Kaufman, K.R., et al., A global needs assessment in times of a global crisis: world psychiatry response to the COVID-19 pandemic. BJPsych Open, 2020. 6(3): p. e48.

36. Park, J.S., et al., Mental Health of Nurses Working at a Government-designated Hospital During a MERS-CoV Outbreak: A Cross-sectional Study. Arch Psychiatr Nurs, 2018. 32(1): p. 2-6.

37. Kim, J.S. and J.S. Choi, Factors Influencing Emergency Nurses' Burnout During an Outbreak of Middle East Respiratory Syndrome Coronavirus in Korea. Asian Nurs Res (Korean Soc Nurs Sci), 2016. 10(4): p. 295-299. 
38. Maunder, R., et al., The immediate psychological and occupational impact of the 2003 SARS outbreak in a teaching hospital. CMAJ, 2003. 168(10): p. 1245-1251.

39. Bai, Y., et al., Survey of stress reactions among health care workers involved with the SARS outbreak. Psychiatric Services, 2004. 55(9): p. 1055-1057.

40. McAlonan, G.M., et al., Immediate and sustained psychological impact of an emerging infectious disease outbreak on health care workers. Canadian Journal of Psychiatry, 2007. 52(4): p. 241-247.

41. Elbay, R.Y., et al., Depression, anxiety, stress levels of physicians and associated factors in Covid-19 pandemics. Psychiatry Research, 2020. 290: p. 113130.

42. Restauri, N. and A.D. Sheridan, Burnout and Posttraumatic Stress Disorder in the Coronavirus Disease 2019 (COVID-19) Pandemic: Intersection, Impact, and Interventions. Journal of the American College of Radiology, 2020. 17(7): p. 921-926.

43. Fessell, D. and C. Cherniss, Coronavirus Disease 2019 (COVID-19) and Beyond: Micropractices for Burnout Prevention and Emotional Wellness. Journal of the American College of Radiology, 2020. 17(6): p. 746-748.

44. Hopwood, T.L. and N.S. Schutte, A meta-analytic investigation of the impact of mindfulness-based interventions on post traumatic stress. Clin Psychol Rev, 2017. 57: p. 12-20.

45. Wu, P., et al., The Psychological Impact of the SARS Epidemic on Hospital Employees in China: Exposure, Risk Perception, and Altruistic Acceptance of Risk. The Canadian Journal of Psychiatry, 2009. 54(5): p. 302-311.

46. Liu, Q., et al., The experiences of health-care providers during the COVID-19 crisis in China: a qualitative study. 2020.

47. Petzold, M.B., J. Plag, and A. Ströhle, Dealing with psychological distress by healthcare professionals during the COVID-19 pandemia. Nervenarzt, 2020. 91(5): p. 417-421.

48. Xiao, X., et al., Psychological impact of healthcare workers in China during COVID-19 pneumonia epidemic: A multi-center cross-sectional survey investigation. Journal of Affective Disorders, 2020. 274: p. 405-410.

49. Sasangohar, F., et al., Provider Burnout and Fatigue During the COVID-19 Pandemic: Lessons Learned From a High-Volume Intensive Care Unit. Anesthesia and analgesia, 2020. 131(1): p. 106-111.

50. Blake, H., et al., Mitigating the psychological impact of COVID-19 on healthcare workers: a digital learning package. 2020. 17(9): p. 2997.

\section{Supplementary Files}

This is a list of supplementary files associated with this preprint. Click to download.

- MBllicensemsyou.pdf 